초등학생 대상 채소 관련 영양교육의 효과 평가

\author{
이선옥 ${ }^{1} \cdot$ 김현아 $^{2+}$ \\ ${ }^{1}$ 경남대학교 교육대학원 영양교육전공 \\ 2경남대학교 식품영양학과
}

\title{
Evaluation of Effectiveness of Vegetable-related Nutrition Education for Elementary School Students
}

\author{
Sun-Ok Lee ${ }^{1}$ and Hyun-Ah Kim ${ }^{2+}$ \\ ${ }^{1}$ Nutrition Education Major, Graduate School of Education and \\ ${ }^{2}$ Dept. of Food and Nutritional Sciences, Kyungnam University, Gyeongnam 631-701, Korea
}

\begin{abstract}
The purpose of this study was to evaluate the effectiveness of vegetable-related nutrition education for fourth grade elementary school students in Gyeongnam province. A comparative analysis of nutritional knowledge on vegetables, vegetable preferences, and vegetable intake in school foodservices were assessed between a control group and an experimental group. The control and experimental group contained 62 and 67 students, respectively, and the experimental group received nutritional education in four sessions (40 minutes each session) per week. A self-administered survey was conducted before and after this education, and 122 questionnaires (for 61 members of the experimental group and 61 members of control group) were analyzed. In the experimental group, there was a significant $(\mathrm{p}<0.001)$ increase in vegetable-related nutrition knowledge (form 5.02 to 6.10 out of a total score of 9), while there were no significant differences in the control group. Vegetable preference scores also significantly $(\mathrm{p}<0.001)$ increased (from 3.44 to 3.85 on the 5 -point Likert scale) in experimental group, while there were no significant difference in control group. We also observed a significant $(\mathrm{p}<0.001)$ increase in vegetable intake from school foodservices $(89.34 \%$ to $95.49 \%)$ in the experimental group, but there were no significant differences in the control group. In conclusion, a vegetable-related nutrition education for fourth grade elementary school students was effective at improving the nutritional knowledge of vegetables, vegetable preferences, and vegetable intake from school foodservices. Therefore, to encourage the vegetable-related right dietary habits, sustainable, and systematic nutrition education programs should be implemented for elementary students.
\end{abstract}

Key words: vegetable-related nutrition education, effectiveness, nutrition knowledge, vegetable preference, vegetable intake

\section{서 론}

초등학교 시기의 바람직한 식습관 형성은 매우 중요하다. 신체적, 정신적 성장에 직접적으로 영향을 미칠 뿐만 아니라 청소년기의 건강과 성장 그리고 나아가 일생의 건강에 장기 적이고 간접적인 영향을 미치기 때문이다.

초등학생의 가장 큰 식생활 문제점으로 많은 연구(1-6)에 서 '편식'이 꾸준히 지적되고 있으며, 편식하는 음식으로는 채소류가 가장 많은 부분을 차지하고 있다 $(7,8)$. 채소류 및 채소 반찬류에 대한 기호도가 낮을 뿐만 아니라(9-11), 하루 채소 섭취량은 권장 수준에 못 미치며(12), 학교급식에서 채 소류의 잔반율이 다른 반찬류에 비해 높은 수준을 보이고 있다(13).
이러한 낮은 수준의 채소류 섭취량은 한국인의 식이섬유 섭취량의 전반적인 감소 현상의 원인 중의 하나로 지적되고 있다(14). 2010년에 수행된 $\mathrm{Na}$ 등(12)의 연구에 의하면 조사 대상인 초등학생의 채소섭취량은 $188.7 \mathrm{~g}$ 이었으며, 2011년 국민건강통계 자료(15)에 의하면 1 9세의 채소류 섭취량은 $110.7 \mathrm{~g}, 10 \sim 18$ 세는 $207.4 \mathrm{~g}$ 으로 보고되었다.

채소 관련 영양 교육 및 섭취 증진은 초등학생의 영양지 식, 식행동, 섭취량 및 자아효능감에 긍정적인 영향을 미치 는 것으로 보고된 바 있다(8,12,16-18). 즉 초등학생의 가장 주요한 식생활 문제점인 편식으로 인한 채소류의 섭취량 감 소는 미량영양소의 결핍을 유발할 수 있어 개인적 수준에서 는 영양불균형과 건강의 위험을 초래할 수 있으며, 사회적 수준에서는 학교급식에서의 잔반량 증가를 초래하여 자원

${ }^{\dagger}$ Corresponding author. E-mail: hakim@kyungnam.ac.kr Phone: 82-55-249-2220, Fax: 82-0505-96-2184 
낭비 및 환경오염을 야기할 수 있다. 따라서 초등학생의 올 바른 식습관 형성은 개인적 수준에서 뿐만 아니라 사회적 수준에서도 매우 중요하다. 이러한 문제의 해결을 위해서 기호도와 섭취량이 낮은 채소류의 섭취 증대를 위한 다양한 노력이 절실히 필요하다.

초등학생 대상으로 채소와 관련하여 수행된 연구를 살펴 보면 채소류의 섭취 실태와 선호도에 대한 연구가 대부분이 며 $5,8-11,19)$, 균형식 위주의 일반적인 영양교육을 실시한 후 측정 변수 중의 일부를 채소 관련 변수로 측정한 연구가 있을 뿐 $(20,21)$ 채소 관련 영양교육의 효과성에 대한 체계적 인 연구는 아직까지 활발히 이루어지지 않고 있다.

$\operatorname{Park}(20)$ 은 편식 지도를 위해 균형식을 주제로 영양교육 을 실시한 결과 기호도가 좋았던 채소류를 제외한 모든 채소 류의 기호도가 유의하게 증가하였다고 보고하였다. Yoon 등 (21)의 연구에서도 마찬가지로 균형식 위주의 영양교육을 실시한 결과 식품 섭취의 다양성에 유의한 변화를 보였으며, 특히 담색채소와 녹황색채소의 유의한 섭취 증가를 보여 영 양교육의 효과성을 보고한 바 있다. 하지만 이들 연구는 균 형식 위주의 일반적인 영양교육을 실시한 후 일부 변수로써 채소의 기호도(20)와 섭취 다양성(21)을 측정하였을 뿐 채소 와 관련하여 좀 더 구체적인 영양교육이 이루어지지 않은 점과 채소와 관련하여 다양한 측정 변수를 사용하지 못 한 점에서 제한점이 있다.

지금까지 이루어진 채소 관련 영양교육의 효과성을 측정 한 논문을 살펴보면, Chang과 Lee(3)는 채소 기피 아동을 대상으로 채소 관련 영양교육을 실시하여 채소류에 대한 기 호도가 유의적으로 증가하는 결과를 보였는데 특히 기피하 는 채소(고추, 호박, 도라지, 고사리, 버섯)에 대한 기호도가 향상되어 매우 주요한 연구 결과를 제시하였다. 또한 영양지 식도 마찬가지로 교육집단에서 유의한 향상을 보여 영양교 육의 효과성을 입증하였다. Lee(22)는 초등학생을 대상으로 영양교육 전후의 채소 관련 영양지식의 유의한 변화가 있었 으며, 시금치의 섭취량이 유의한 증가를 보여 영양교육이 채소 섭취 행동의 변화를 유도함을 보고하였다. Suh와 Chung(16)의 연구에서는 채소와 과일 섭취 증진을 위한 영 양교육이 초등학생의 자아효능감에 유의한 영향을 미친다 고 발표하였다. 하지만 Chang과 Lee(3)는 채소류에 대한 기 호도 및 영양지식의 향상에 긍정적인 영향을 미치는 결과를 제시하였으나 실험군과 대조군의 표본수가 15 명이라는 제 한점이 있으며, Lee(22)의 연구에서는 영양교육이 채소섭취 행동의 변화를 유도하는 결과를 도출할 수 있었지만, 대조군 이 없이 실험군을 대상으로 실시한 한계가 있었다. 또한 Suh 와 Chung(16)의 연구도 마찬가지로 채소와 과일 섭취 증진 을 위한 영양교육이 자아효능감의 향상에 기여함을 발표하 였지만 대조군 없이 실험군만을 대상으로 실시한 제한점이 있다.

이에 본 연구에서는 창원지역에 소재한 $\mathrm{A}$ 초등학교 4 학년
을 대상으로 실험군과 대조군의 두 집단으로 구분하여 두집 단사전사후측정 실험설계방법을 적용하여 채소 관련 영양 교육의 효과성을 평가하고자 하였다. 효과성은 영양지식(채 소 인지도, 채소 관련 영양지식), 채소에 대한 기호도 그리고 채소 섭취 행동(채소 섭취 경험, 학교급식 채소반찬의 섭취 율)의 3 가지 측면에서 변화 정도를 측정하였다.

\section{대상 및 방법}

\section{영양교육 대상 및 기간}

본 연구에서는 두집단사전사후측정 실험설계(two group pretest-posttest design)에 의하여(23-26) 채소 관련 영양교 육의 효과성을 측정하고자 하였다. 영양교육 대상은 경상남 도 창원시에 소재한 $\mathrm{A}$ 초등학교 4학년 4 개 반 129 명으로 교 육집단 67명(2개 반), 비 교육집단 62명(2개 반)으로 구성하 였다. 2010년 10월 4일부터 10월 25일까지 교육집단을 대상 으로 총 4 회(주 1 회, 회당 교육시간 40 분)의 채소 관련 영양 교육을 영양교사가 직접 실시하였다. 영양교육의 효과성 평 가를 위해 교육집단과 비교육집단을 대상으로 각각 교육 전 과 교육 후 설문 조사를 2회 실시하였다. 총 129 개의 설문지 중 부적절한 설문을 제외한 분석 가능한 설문지 총 122 부(교 육집단 61 부, 비교육집단 61 부)를 최종 분석에 사용하였다.

\section{영양교육 내용}

영양교육 내용은 경상남도교육청에서 발행한 식생활 교 육 자료(27)을 참고하여 구성하였다(Table 1). 영양교육의 구체적인 내용은 다음과 같다. 1 주차에는 식품구성탑의 개 념, 영양소의 개념 및 기능, 식품구성탑 각층의 해당 식품, 균형식과 식품구성탑의 관계에 대한 내용을 파워포인트자 료, 영양소 카드, 영양소별 식품 사진 등의 매체를 이용하여 교육하였다. 2 주차에는 식이섬유의 개념 및 역할, 식이섬유 포함 식품을 주요 내용으로 하여 파워포인트, 동영상, 판넬, 사진, 활동지, 모듬 활동을 이용하여 교육하였다. 3 주차에는 채소 섭취의 장점, 다양한 채소 이름 및 종류를 주요 내용으 로 파워포인트, 교재, 개별 활동을 이용하여 교육하였다. 4 주 차에는 채소의 종류별 해당 식품과 채소를 이용해서 만든 음식 소개를 주요 내용으로 채소 실물 모형, 파워포인트, 교 재, 모듬 활동을 이용하여 교육하였다.

\section{영양교육 효과 평가}

채소 관련 영양교육의 효과 평가를 위한 설문지 개발을 위하여 선행연구 $(5,9,10,13,28)$ 를 참고하여 초등학교 4 학년 학생의 수준에 적합하도록 재구성하였다. 예비조사를 거쳐 설문 내용과 문항을 수정·보완하여 최종 설문지를 완성하 였다.

설문지는 조사대상의 일반사항, 영양지식, 채소 기호도, 채소 섭취 행동의 4 개 부분으로 구성하였다. 첫째, 조사대상 의 일반사항으로 성별, 아버지 연령, 어머니 연령, 가족 구성, 
Table 1. Four-week vegetable nutrition education program for elementary school students

\begin{tabular}{|c|c|c|c|}
\hline Week & Subject & Contents & Medium \\
\hline 1 & $\begin{array}{l}\text { Understanding of } \\
\text { food pyramid }\end{array}$ & $\begin{array}{l}\text { - Introduction of concept of food pyramid } \\
\text { - Introduction of nutrients (protein, fat, carbohydrate, vitamin and } \\
\text { mineral) and its functions } \\
\text { - Understanding foods and nutrients for food pyramid } \\
\text { - Introduction how to sing a song about food pyramid } \\
\text { - Understanding relationship between food pyramid and balanced } \\
\text { diet }\end{array}$ & $\begin{array}{l}\text { - Powerpoint } \\
\text { - Picture of food } \\
\text { - Board }\end{array}$ \\
\hline 2 & $\begin{array}{l}\text { Understanding of } \\
\text { fiber }\end{array}$ & $\begin{array}{l}\text { - Introduction of concept and roles of fiber } \\
\text { - Understanding foods that contain fiber } \\
\text { - Leading group activity to present the menu which contains fiber }\end{array}$ & $\begin{array}{l}\text { - Powerpoint } \\
\text { - Video } \\
\text { - Panel } \\
\text { - Picture } \\
\text { - Activity record } \\
\text { - Group activity }\end{array}$ \\
\hline 3 & $\begin{array}{l}\text { Understanding of } \\
\text { vegetables ( I ) }\end{array}$ & $\begin{array}{l}\text { - Introduction of functions of vegetables and good points of } \\
\text { vegetable intake } \\
\text { - Understanding names of various vegetables } \\
\text { - Understanding categories of vegetables }\end{array}$ & $\begin{array}{l}\text { - Powerpoint } \\
\text { - Textbook } \\
\text { - Individual activity }\end{array}$ \\
\hline 4 & $\begin{array}{l}\text { Understanding of } \\
\text { vegetables }(I I)\end{array}$ & $\begin{array}{l}\text { - Understanding various vegetables according to categorization } \\
\text { - Introduction of various vegetable dishes } \\
\text { - Introduction of how to sing a tomato song }\end{array}$ & $\begin{array}{l}\text { - Powerpoint } \\
\text { - Food model } \\
\text { - Textbook } \\
\text { - Group activity }\end{array}$ \\
\hline
\end{tabular}

식사준비자, 건강 정도의 6 개 문항으로 구성하였으며, 둘째, 영양지식은 채소 인지도와 채소 관련 영양지식의 문항으로 구성하였다. 채소 인지도는 선행 연구 $(5,9,10,28)$ 를 참고로 하여 학교급식에서 제공되는 대표적인 29가지 채소류에 대 하여 알고 있는지 응답하도록 하여 '예'라고 응답한 경우는 1 점, '아니오'라고 응답한 경우는 0점을 기준으로 산출하여 총점(0 29점)을 산출하였으며, 총점이 높을수록 채소에 대 한 인지도가 높은 것을 의미한다. 채소 관련 영양지식을 측 정하기 위해 총 9 개 문항으로 구성하였으며 $(10,28)$, 각 문항 에 대하여 '정답'인 경우는 1점, '오답' 혹은 '잘 모르겠다'라고 응답한 경우에는 0 점을 기준으로 총점(0 9점)을 산출하였 으며 총점이 높을수록 영양지식의 수준이 높음을 의미한다. 셋째, 채소 기호도는 29 가지 채소류 $(5,9,10,28)$ 에 대하여 5 점 척도(1, 매우 싫어한다; 5 , 매우 좋아한다)를 이용하여 측정 하였다. 넷째, 채소 섭취 행동은 채소 섭취 경험 정도 및 학교 급식에서 제공되는 채소 반찬의 섭취율의 문항으로 구성하 였다. 채소 섭취 경험 정도는 29 가지 채소류 $(5,9,10)$ 에 대하 여 섭취 경험이 있는 경우는 1 점, 섭취 경험이 없는 경우는 0점을 기준으로 총점(0 29점)을 산출하였으며 총점이 높을 수록 섭취 경험이 많은 것을 의미한다. 학교급식에서 제공되 는 채소 반찬의 섭취율을 조사하기 위해 채소 반찬, 시금치 반찬, 배추김치, 깍두기의 4 개에 대하여 평상시 섭취하는 정 도를 설문지에 응답하도록 하였다. '전혀 안 먹었다' $0 \%, 1 / 4$ 만큼 먹었다' $25 \%$, ' $1 / 2$ 만큼 먹었다' $50 \%$, ' $3 / 4$ 만큼 먹었다' $75 \%$, '다 먹었다' $100 \%$ 로 환산하여 섭취량을 산출하였다 (13). 이상의 설문 내용으로 구성된 동일한 설문지를 교육 집단과 비교육 집단을 대상으로 각각 교육 전과 교육 후에 배포하여 조사하였으며, 채소 관련 영양교육에 대한 인식을
조사하기 위하여 교육집단의 교육 후 설문 조사 내용에는 영양 교육 수업의 훙미 정도, 영양교육이 영양지식 향상에 도움 주는 정도, 영양교육 후 채소 반찬 제공시 섭취 행동, 영양교육 후 섭취하는 채소 반찬의 증가 정도, 영양교육 후 매끼 채소 섭취 여부의 6 개 문항을 추가하였다.

\section{통계처리}

본 연구에서의 통계 분석을 위해 SPSS/WIN Program (Ver 15.0, SPSS Inc., Chicago, IL, USA)을 이용하였으며 그 분석방법은 다음과 같다. 교육집단과 비교육집단의 일반 사항의 비교를 위해 카이 검증을 실시하였으며, 교육집단과 비교육집단의 동질성 검증을 위해 독립표본 $\mathrm{t}$-검정을 실시 하였다. 교육집단과 비교육집단에 대하여 채소 인지도, 채소 관련 영양지식, 채소 기호도, 채소 섭취 경험 정도 및 학교급 식 채소 반찬 섭취량의 교육 전후의 비교를 위하여 paired t-test를 실시하였고, 채소 관련 영양교육에 대한 조사대상 의 인식을 조사하기 위하여 빈도분석을 실시하였다.

\section{결과 및 고찰}

\section{조사 대상의 일반 사항}

연구 대상의 일반사항은 Table 2 와 같다. 조사대상 초등학 생의 아버지 연령은 교육집단(80.3\%)과 비교육집단(78.7\%) 모두 40 대가 대부분이었으며, 어머니 연령은 교육집단과 비 교육집단 모두 30 대와 40 대의 비율이 비슷하였다. 가족구성 은 핵가족이라는 응답이 교육집단 $(83.6 \%)$ 과 비교육집단 (70.5\%)에서 대부분을 차지하였다. 식사준비자는 교육집단 과 비교육집단 모두 어머니라는 응답이 가장 많았다. 건강정 
Table 2. General characteristics of subject

\begin{tabular}{|c|c|c|c|c|c|}
\hline Variables & Item & Total & Experimental group & Control group & $x^{2}$ \\
\hline Gender & $\begin{array}{l}\text { Male } \\
\text { Female }\end{array}$ & $\begin{array}{l}70(57.4) \\
52(42.6)\end{array}$ & $\begin{array}{l}36(59.0) \\
25(41.0)\end{array}$ & $\begin{array}{l}34(55.7) \\
27(44.3)\end{array}$ & 0.13 \\
\hline Age of father (yr) & $\begin{array}{l}30 \sim 39 \\
40 \sim 49\end{array}$ & $\begin{array}{l}25(20.5) \\
97(79.5)\end{array}$ & $\begin{array}{l}12(19.7) \\
49(80.3)\end{array}$ & $\begin{array}{l}13(21.3) \\
48(78.7)\end{array}$ & 0.05 \\
\hline Age of mother (yr) & $\begin{array}{l}30 \sim 39 \\
40 \sim 49\end{array}$ & $\begin{array}{l}67(54.9) \\
55(45.1)\end{array}$ & $\begin{array}{l}33(54.1) \\
28(45.9)\end{array}$ & $\begin{array}{l}34(55.7) \\
27(44.3)\end{array}$ & 0.03 \\
\hline Composition of family & $\begin{array}{l}\text { Large family } \\
\text { Small family }\end{array}$ & $\begin{array}{l}28(23.0) \\
94(77.0)\end{array}$ & $\begin{array}{l}10(16.4) \\
51(83.6)\end{array}$ & $\begin{array}{l}18(29.5) \\
43(70.5)\end{array}$ & 2.97 \\
\hline Meal maker & $\begin{array}{l}\text { Mother } \\
\text { Grandmother } \\
\text { Father } \\
\text { Etc }\end{array}$ & $\begin{array}{r}104(85.2) \\
8(6.6) \\
6(4.9) \\
4(3.3)\end{array}$ & $\begin{array}{r}52(85.2) \\
2(3.3) \\
5(8.2) \\
2(3.3)\end{array}$ & $\begin{array}{r}52(85.2) \\
6(9.8) \\
1(1.6) \\
2(3.3)\end{array}$ & 4.67 \\
\hline State of health & $\begin{array}{l}\text { Not healthy at all } \\
\text { Not healthy } \\
\text { Neutral } \\
\text { Healthy } \\
\text { Very healthy }\end{array}$ & $\begin{aligned} 3 & (2.5) \\
5 & (4.1) \\
23 & (18.8) \\
60 & (49.2) \\
31 & (25.4)\end{aligned}$ & $\begin{array}{r}1(1.6) \\
3(4.9) \\
9(14.8) \\
32(52.5) \\
16(26.2)\end{array}$ & $\begin{array}{r}2(3.3) \\
2(3.3) \\
14(23.0) \\
28(45.9) \\
15(24.6)\end{array}$ & 1.92 \\
\hline \multicolumn{2}{|c|}{ Total } & & $61(100.0)$ & $61(100.0)$ & \\
\hline
\end{tabular}

Table 3. Homogeneity test of experimental and control group

\begin{tabular}{|c|c|c|c|c|c|}
\hline Category & Item & Group & $\mathrm{N}$ & Mean \pm SD & $\mathrm{t}$-value \\
\hline \multirow{2}{*}{$\begin{array}{l}\text { Nutrition } \\
\text { knowledge }\end{array}$} & Awareness of vegetables ${ }^{1)}$ & $\begin{array}{l}\text { Experimental group } \\
\text { Control group }\end{array}$ & $\begin{array}{l}61 \\
61\end{array}$ & $\begin{array}{l}27.00 \pm 2.44 \\
27.25 \pm 2.25\end{array}$ & -0.58 \\
\hline & $\begin{array}{l}\text { Nutrition knowledge } \\
\text { about vegetables }{ }^{2}\end{array}$ & $\begin{array}{l}\text { Experimental group } \\
\text { Control group }\end{array}$ & $\begin{array}{l}61 \\
61\end{array}$ & $\begin{array}{l}5.02 \pm 1.44 \\
5.49 \pm 1.78\end{array}$ & -1.62 \\
\hline \multicolumn{2}{|c|}{ Preference of vegetables ${ }^{3)}$} & $\begin{array}{l}\text { Experimental group } \\
\text { Control group }\end{array}$ & $\begin{array}{l}61 \\
61\end{array}$ & $\begin{array}{l}3.44 \pm 0.77 \\
3.21 \pm 0.72\end{array}$ & 1.68 \\
\hline \multirow{2}{*}{$\begin{array}{l}\text { Intake of } \\
\text { vegetables }\end{array}$} & $\begin{array}{l}\text { Experience of various } \\
\text { vegetables intake }\end{array}$ & $\begin{array}{l}\text { Experimental group } \\
\text { Control group }\end{array}$ & $\begin{array}{l}61 \\
61\end{array}$ & $\begin{array}{l}25.62 \pm 3.39 \\
25.97 \pm 3.16\end{array}$ & -0.58 \\
\hline & $\begin{array}{l}\text { Vegetable dishes intake } \\
\text { in school foodservice }(\%)^{5)}\end{array}$ & $\begin{array}{l}\text { Experimental group } \\
\text { Control group }\end{array}$ & $\begin{array}{l}61 \\
61\end{array}$ & $\begin{array}{l}89.34 \pm 13.61 \\
92.21 \pm 13.58\end{array}$ & -1.17 \\
\hline
\end{tabular}

${ }^{1)}$ Total score: $29 .{ }^{2)}$ Total score: $9 .{ }^{3)} 5$-point Likert scale (1, dislike very much; 5, like very much). ${ }^{4)}$ Total score: 29.

${ }^{5)}$ Calculated based on conversion of 'not eat at all' (0\%), 'eat 1/4' (25\%), 'eat 1/2' (50\%), 'eat 3/4' (75\%), 'eat all' (100\%).

도는 두 집단 모두 '건강하다' $52.5 \%, 45.9 \%)$ 와 '매우 건강하 다' $(26.2 \%, 24.6)$ 는 응답이 대부분이었다. 교육집단과 비교 육집단 간에 일반 사항의 유의한 차이는 없었다.

\section{교육집단과 비교육집단의 사전 동질성 검사}

채소 관련 영양교육의 효과를 검증하기 위해 우선 영양교 육을 실시한 교육집단과 영양교육을 실시하지 않은 비교육 집단의 사전 동질성 검사를 실시하였으며 그 결과는 Table 3 에 제시하였다. 두 집단의 사전 동질성 검증 결과 영양지식,
채소 기호도, 채소 섭취 모두에서 집단 간 차이가 유의하지 않아 두 집단이 동질집단임을 확인할 수 있었다.

\section{채소 관련 영양교육이 영양지식에 미치는 영향}

채소 관련 영양교육이 영양지식에 미치는 영향은 Table 4 와 같다. 본 연구에서는 채소 관련 영양교육의 효과성 측정 항목인 영양지식은 크게 채소 인지도와 채소 관련 영양지식 으로 나누어 측정하였다.

우선 채소 인지도를 살펴보면 교육집단은 교육 전 $(\mathrm{M}=$

Table 4. Vegetable-related nutrition education's effect on nutrition knowledge and awareness of vegetables

\begin{tabular}{|c|c|c|c|c|c|c|}
\hline Nutrition knowledge & Group & $\mathrm{N}$ & $\begin{array}{c}\text { Pre-test } \\
\text { Mean } \pm \text { SD }\end{array}$ & $\begin{array}{l}\text { Post-test } \\
\text { Mean } \pm \text { SD }\end{array}$ & Difference & t-value \\
\hline Awareness of vegetables ${ }^{1)}$ & $\begin{array}{l}\text { Experimental group } \\
\text { Control group }\end{array}$ & $\begin{array}{l}61 \\
61\end{array}$ & $\begin{array}{l}27.00 \pm 2.44 \\
27.25 \pm 2.25\end{array}$ & $\begin{array}{l}28.64 \pm 0.91 \\
27.87 \pm 1.97\end{array}$ & $\begin{array}{l}1.64 \\
0.62\end{array}$ & $\begin{array}{l}-5.91^{* * *} \\
-3.38^{* * *}\end{array}$ \\
\hline $\begin{array}{l}\text { Nutrition knowledge about } \\
\text { vegetables }\end{array}$ & $\begin{array}{l}\text { Experimental group } \\
\text { Control group }\end{array}$ & $\begin{array}{l}61 \\
61\end{array}$ & $\begin{array}{l}5.02 \pm 1.44 \\
5.49 \pm 1.78\end{array}$ & $\begin{array}{l}6.10 \pm 1.63 \\
5.90 \pm 1.40\end{array}$ & $\begin{array}{l}1.08 \\
0.41\end{array}$ & $\begin{array}{l}-4.82^{* * *} \\
-1.97\end{array}$ \\
\hline
\end{tabular}

${ }^{1)}$ Total score: $29 .{ }^{2)}$ Total score: $9 .{ }^{* * *} \mathrm{p}<0.001$. 
Table 5. Vegetable-related nutrition education's effect on preference of vegetables

\begin{tabular}{|c|c|c|c|c|c|c|}
\hline & \multirow{2}{*}{ Group } & \multirow{2}{*}{$\mathrm{N}$} & Pre-test $^{1)}$ & Post-test $^{1)}$ & \multirow{2}{*}{ Difference } & \multirow{2}{*}{ t-value } \\
\hline & & & Mean \pm SD & Mean \pm SD & & \\
\hline $\begin{array}{l}\text { Preference of } \\
\text { vegetables } 1 \text { ) }\end{array}$ & $\begin{array}{l}\text { Experimental group } \\
\text { Control group }\end{array}$ & $\begin{array}{l}61 \\
61\end{array}$ & $\begin{array}{l}3.44 \pm 0.77 \\
3.21 \pm 0.72\end{array}$ & $\begin{array}{l}3.85 \pm 0.76 \\
3.25 \pm 0.70\end{array}$ & $\begin{array}{l}0.42 \\
0.04\end{array}$ & $\begin{array}{l}-9.15^{* * *} \\
-1.32\end{array}$ \\
\hline
\end{tabular}

${ }^{1)}$ Average of preference for 29 vegetables measured by 5 point Likert scale (1, dislike very much; 5 , like very much). ${ }^{* * *} \mathrm{p}<0.001$.

27.00)에 비해 교육 후 $(\mathrm{M}=28.64)$ 에 1.64점의 증가가 나타났 으며, 비교육집단도 교육 전 $(\mathrm{M}=27.25)$ 에 비해 교육 후 $(\mathrm{M}=$ 27.87)에 0.62점의 증가를 보였다. 통계 분석 결과 교육집단 $(\mathrm{p}<0.001)$ 과 비교육집단 $(\mathrm{p}<0.001)$ 모두에서 유의적인 차이 를 보여 교육 후 두 집단 모두 채소 인지도가 높아졌다. 하지 만 교육집단이 비교육집단에 비해 더 큰 폭의 증가를 보였다.

채소 관련 영양교육이 초등학생의 채소 관련 영양지식에 미치는 효과를 검증한 결과 교육집단은 교육 전 $(\mathrm{M}=5.02)$ 에 비해 교육 후 $(\mathrm{M}=6.10)$ 에 1.08점이 향상되었으며 유의적인 차이를 나타내었다 $(\mathrm{p}<0.001)$. 하지만 비교육집단은 교육 전 $(\mathrm{M}=5.49)$ 에 비해 교육 후 $(\mathrm{M}=5.90)$ 에 0.41 점의 증가를 보이 긴 하였으나 유의적인 차이는 없었다. 따라서 본 연구에서 실시한 채소 관련 영양교육이 초등학생의 채소 관련 영양지 식을 높이는 데 효과가 있다고 볼 수 있다.

채소 기피 아동에 대한 영양교육 효과를 평가한 연구(3)에 서 영양교육을 실시하지 않은 대조군에서는 유의한 차이가 없었지만 영양교육을 실시한 실험군에서 영양지식의 유의 적인 향상이 있음이 보고된 바 있으며, $\operatorname{Park}(20)$ 의 연구에서 도 영양교육이 영양지식의 유의적인 증가에 영향을 미친다 고 발표하여 본 연구 결과와 같았다.

\section{채소 관련 영양교육이 채소 기호도에 미치는 영향}

채소 관련 영양교육이 초등학생들의 채소 기호도에 미치 는 효과를 분석한 결과는 Table 5에 나타내었다. 29종의 채 소에 대한 기호도의 평균값을 분석한 결과 교육집단은 교육
전 $(\mathrm{M}=3.44)$ 에 비해 교육 후 $(\mathrm{M}=3.85)$ 에 0.42 점의 기호도 증 가가 나타났으며 그 차이는 유의하였다 $(\mathrm{p}<0.001)$. 반면 비교 육집단은 교육 전 $(\mathrm{M}=3.21)$ 과 교육 후 $(\mathrm{M}=3.25)$ 의 변화가 0.04 로 그 차이가 유의하지 않았다. 따라서 본 연구에서 실시 한 영양교육 프로그램이 초등학생의 채소 기호도를 높이는 효과가 있다고 할 수 있었다. 선행 연구 $(8,20)$ 에서도 영양 교육이 초등학생들이 기피하는 채소류에 대한 기호도 향상 에 영향을 미친다고 보고하여 본 연구 결과와 유사하였다. 즉 영양교육은 학생들의 채소에 대한 기호도 향상에 긍정적 인 영향을 미친다고 할 수 있다.

\section{채소 관련 영양교육이 채소 섭취 행동에 미치는 영향}

채소 관련 영양교육이 초등학생들의 채소 섭취 행동에 미 치는 효과를 조사하기 위한 설문 조사 결과는 Table 6과 같 다. 채소 섭취 행동은 크게 29 종의 채소에 대한 섭취 경험의 변화와 학교급식 채소 반찬의 섭취율의 변화의 2 가지 측면 에서 조사하였으며, 교육 집단과 비교육 집단의 두 집단을 대상으로 교육 전후에 동일한 설문 조사를 실시하여 교육 전후에 따른 변화를 조사하였다.

우선 29종의 채소에 대한 섭취 경험 정도의 경우 교육집단 은 교육 전 $(\mathrm{M}=25.62)$ 에 비해 교육 후 $(\mathrm{M}=27.74)$ 에 2.11점의 섭취 경험의 증가가 나타났으며, 비교육집단도 교육 전 $(\mathrm{M}=$ 25.97)에 비해 교육 후 $(\mathrm{M}=26.80)$ 에 0.84 점의 증가를 보였다. 교육집단 $(\mathrm{p}<0.001)$ 과 비교육집단 $(\mathrm{p}<0.001)$ 모두 교육 전에 비해 교육 후 채소 섭취 경험이 유의적으로 높아졌다. 즉

Table 6. Vegetable-related nutrition education's effect on vegetable intake (experience of various vegetables intake and vegetable dishes intake of school foodservice)

\begin{tabular}{|c|c|c|c|c|c|c|c|}
\hline Category & Item & Group & $\mathrm{N}$ & Pre-test (\%) & Post-test $(\%)$ & Difference & $\mathrm{t}$-value \\
\hline \multicolumn{2}{|c|}{$\begin{array}{l}\text { Experience of various } \\
\text { vegetables intake }\end{array}$} & Experimental group & 61 & $25.62 \pm 3.39^{3)}$ & $27.74 \pm 2.02$ & 2.11 & $-6.74^{* * *}$ \\
\hline \multirow{5}{*}{$\begin{array}{l}\text { Vegetable dishes } \\
\text { Intake in school } \\
\text { foodservice }(\%)^{2)}\end{array}$} & Vegetables dishes & $\begin{array}{l}\text { Experimental group } \\
\text { Control group }\end{array}$ & 61 & $\begin{array}{l}86.07 \pm 16.79 \\
88.11 \pm 18.03\end{array}$ & $\begin{array}{l}90.57 \pm 14.55 \\
88.93 \pm 17.40\end{array}$ & $\begin{array}{l}0.04 \\
4.51 \\
0.82\end{array}$ & $\begin{array}{l}-1.96 \\
-1.00\end{array}$ \\
\hline & Spinach dishes & $\begin{array}{l}\text { Experimental group } \\
\text { Control group }\end{array}$ & $\begin{array}{l}61 \\
61\end{array}$ & $\begin{array}{l}92.21 \pm 15.51 \\
90.16 \pm 19.51\end{array}$ & $\begin{array}{l}97.95 \pm 8.29 \\
90.98 \pm 18.84\end{array}$ & $\begin{array}{l}5.74 \\
0.82\end{array}$ & $\begin{array}{l}-2.68^{* *} \\
-0.50\end{array}$ \\
\hline & Paechu Kimchi & $\begin{array}{l}\text { Experimental group } \\
\text { Control group }\end{array}$ & $\begin{array}{l}61 \\
61\end{array}$ & $\begin{array}{l}89.75 \pm 16.69 \\
94.26 \pm 17.91\end{array}$ & $\begin{array}{l}96.72 \pm 9.66 \\
96.72 \pm 14.77\end{array}$ & $\begin{array}{l}6.97 \\
2.46\end{array}$ & $\begin{array}{l}-3.57^{* * *} \\
-1.62\end{array}$ \\
\hline & Kkakdugi & $\begin{array}{l}\text { Experimental group } \\
\text { Control group }\end{array}$ & $\begin{array}{l}61 \\
61\end{array}$ & $\begin{array}{l}89.34 \pm 17.36 \\
96.31 \pm 15.03\end{array}$ & $\begin{array}{l}96.72 \pm 10.68 \\
97.95 \pm 8.29\end{array}$ & $\begin{array}{l}7.38 \\
1.64\end{array}$ & $\begin{array}{l}-3.92^{* * *} \\
-1.00\end{array}$ \\
\hline & Average & $\begin{array}{l}\text { Experimental group } \\
\text { Control group }\end{array}$ & $\begin{array}{l}61 \\
61\end{array}$ & $\begin{array}{l}89.34 \pm 13.61 \\
92.21 \pm 13.58\end{array}$ & $\begin{array}{l}95.49 \pm 7.83 \\
93.65 \pm 10.79\end{array}$ & $\begin{array}{l}6.15 \\
1.43\end{array}$ & $\begin{array}{l}-3.63^{* * *} \\
-1.25\end{array}$ \\
\hline
\end{tabular}

\footnotetext{
${ }^{11}$ Total score: 29 .

${ }^{2)}$ Calculated based on conversion of 'not eat at all' (0\%), 'eat 1/4' (25\%), 'eat 1/2' (50\%), 'eat 3/4' (75\%), 'eat all' (100\%).

${ }^{3)}$ Mean \pm SD. ${ }^{* *} \mathrm{p}<0.01,{ }^{* * *} \mathrm{p}<0.001$.
} 
채소 섭취 경험 점수의 유의한 증가는 좀 더 다양한 채소를 섭취한 경험이 있다는 것으로 해석할 수 있으며, 두 집단 모두에서 채소 섭취 경험이 다양해졌다고 할 수 있다. 앞서 Table 4에서 제시한 29종의 채소에 대한 인지도의 변화가 교육집단뿐만 아니라 비교육집단에서도 유의한 증가를 보 였으며, 29 종의 채소에 대한 섭취 경험 정도에서도 마찬가지 로 교육집단뿐만 아니라 비교육집단에서 유의한 증가를 보 인 것은 채소에 대한 인지도와 섭취 경험이 서로 연관성이 있음을 보여주는 것이라고 할 수 있다. 또한 채소에 대한 인지도와 섭취 경험 정도가 비교육집단에서도 유의한 변화 를 보인 것은 가정 내에서의 일상 생활, 학교 안에서 이루어 지는 급식 그리고 다른 교과에서도 식품에 대하여 자연스럽 게 배우는 기회가 있기 때문인 것으로 사료된다. 하지만 29 종의 채소에 대한 인지도 부분과 마찬가지로 29 종의 채소에 대한 섭취 경험 정도에서 교육집단이 비교육집단에 비해 더 큰 폭의 증가를 보였으므로 본 연구에서 실시한 채소 관련 영양교육이 초등학생의 채소 섭취 경험을 높이는 효과가 있 다고 볼 수 있다.

채소 관련 영양교육이 학교급식에서 제공되는 채소반찬, 시금치반찬, 배추김치, 깍두기의 4 가지 채소 반찬의 섭취율 의 변화에 미치는 영향을 살펴보면, 채소반찬 섭취율은 교육 전 $(\mathrm{M}=86.07)$ 에 비해 교육 후 $(\mathrm{M}=90.57)$ 에 $4.51 \%$ 의 증가폭을 보이긴 하였지만 유의한 차이는 아니었다. 시금치 반찬의 섭취율은 교육 전 $(\mathrm{M}=92.21)$ 에 비해 교육 후 $(\mathrm{M}=97.95)$ 에 $5.74 \%$ 의 유의한 증가를 나타났으며 $(\mathrm{p}<0.001)$, 배추김치의 섭취율도 교육 전 $(\mathrm{M}=89.75)$ 에 비해 교육 후 $(\mathrm{M}=96.72)$ 에 $6.97 \%$ 의 유의한 증가를 보였고 $(\mathrm{p}<0.001)$ 깍두기의 섭취율 도 교육 전 $(\mathrm{M}=89.34)$ 에 비해 교육 후 $(\mathrm{M}=96.72)$ 에 $7.38 \%$ 의 유의한 증가를 나타냈다 $(\mathrm{p}<0.001)$. 비교육집단은 채소반찬,
시금치반찬, 배추, 깍두기 김치의 4 가지 항목 모두에서 섭취 율이 유의하게 증가하지 않았다. 즉 채소 관련 영양교육은 시금치, 배추김치, 깍두기의 섭취율 향상에 효과적임을 알 수 있었다.

다만 시금치, 배추김치, 깍두기의 섭취율은 영양교육에 의 해 유의하게 증가하였음에도 불구하고 채소 반찬의 경우 섭 취율의 변화가 유의하지 않았던 것은 좀 더 다양한 채소에 대한 인지도 및 섭취 경험의 향상이 채소 반찬의 전반적인 섭취율 향상으로의 변화로 이어지지 않았기 때문이라고 사 료된다.

4가지 채소 반찬 섭취율의 평균값을 분석한 결과 교육 집 단은 교육 전 $(\mathrm{M}=89.34)$ 에 비해 교육 후 $(\mathrm{M}=95.49)$ 에 $6.15 \%$ 의 섭취량 증가가 나타났으며 $(\mathrm{p}<0.001)$, 비교육집단은 교육 전 $(\mathrm{M}=92.21)$ 에 비해 교육 후 $(\mathrm{M}=93.65)$ 에 $1.43 \%$ 로 거의 변 화가 없었다.

Chang과 Lee(3), Park(20), Panunzio 등(17)의 연구에서 모두 영양교육으로 인해 아동들의 채소 섭취가 증가하였으 며, Yoon 등(21)의 연구에 의하면 영양교육을 통해 식품섭취 의 다양성 및 식품섭취점수가 양호하게 변화하였고 특히 담 색 채소와 녹황색 채소에서도 유의하게 변화하여 본 연구 결과와 유사하였다.

Park과 $\mathrm{Ku}(29)$ 는 급식에서 제공된 음식을 학생들이 먹지 않는 주된 큰 이유는 무슨 음식인지 몰라서인 경우가 상당 부분을 차지하여 새로운 음식에 대한 막연한 두려움을 해소 할 수 있도록 지도하는 것이 필요하다고 제언한 바 있다. 본 연구에서 영양교육을 통해 시금치, 배추김치, 깍두기의 섭취율이 증가된 것은 채소 관련 영양교육을 통해 채소에 대하여 배움으로써 두려움이나 거부감을 없애는 것이 가능 하였기 때문인 것으로 사료된다.

Table 7. Elementary school students' perception on vegetable-related nutrition education

\begin{tabular}{|c|c|c|c|}
\hline Variables & Item & $\mathrm{N}$ & $\%$ \\
\hline \multirow{3}{*}{ Interesting of vegetable nutrition education } & Not interesting & 4 & 6.6 \\
\hline & Neutral & 16 & 26.2 \\
\hline & Interesting & 41 & 67.2 \\
\hline \multirow{3}{*}{$\begin{array}{l}\text { Helpfulness of vegetable nutrition education } \\
\text { for nutrition knowledge }\end{array}$} & Not helpful & 1 & 1.6 \\
\hline & Neutral & 22 & 36.1 \\
\hline & Helpful & 38 & 62.3 \\
\hline \multirow{5}{*}{$\begin{array}{l}\text { Eating behavior of vegetable dishes after } \\
\text { vegetable nutrition education }\end{array}$} & Not eat vegetable dishes & 1 & 1.6 \\
\hline & Eat only favorite vegetable dishes & 1 & 1.6 \\
\hline & Have no idea & 10 & 16.4 \\
\hline & Eat various vegetable dishes little by little & 27 & 44.3 \\
\hline & Eat all vegetable dishes & 22 & 36.1 \\
\hline \multirow{3}{*}{$\begin{array}{l}\text { Increasing of vegetable fishes intake after } \\
\text { vegetable nutrition education }\end{array}$} & Not increased & 3 & 4.9 \\
\hline & Neutral & 32 & 52.5 \\
\hline & Increased & 26 & 42.6 \\
\hline \multirow{3}{*}{ Intake of vegetable every meal } & Not eat vegetable every meal & 2 & 3.3 \\
\hline & Neutral & 35 & 57.4 \\
\hline & Eat vegetable every meal & 24 & 39.3 \\
\hline \multicolumn{2}{|c|}{ Total } & 61 & 100.0 \\
\hline
\end{tabular}




\section{채소 관련 영양교육에 대한 인식}

채소 관련 영양교육에 대한 초등학생의 인식을 조사하기 위해 교육집단의 사후 설문지에 채소 관련 영양교육에 대한 인식 문항을 추가하여 설문조사를 실시한 결과는 Table 7에 제시하였다. 교육집단 61 명중 41명인 $67.2 \%$ 가 '영양교육 수 업이 훙미 있었다'는 응답을 하였으며, '영양교육 수업이 영 양지식의 향상에 도움이 되었다'는 응답은 $62.3 \%$ 였다. 영양 교육 후 채소반찬 제공 시의 섭취 행동에 대해서는 '골고루 조금씩 먹는다'는 응답을 $44.3 \%$ 로 가장 많이 하였고, '영양교 육 후 섭취하는 채소반찬이 늘어났다'는 응답은 $42.6 \%$ 로 나 타났으며, 영양교육 후 매끼 채소를 섭취하는 비율은 $39.3 \%$ 로 나타났다. 전반적으로 채소 관련 영양교육에 대하여 긍정 적으로 인식하고 있음을 알 수 있었다.

Yun과 Yang(30)의 연구에서 영양교육이 식생활에 도움 이 되는 것으로 보고하였듯이 본 연구에서도 영양교육을 통 해 초등학생들의 식생활에 긍정적인 영향을 있음을 알 수 있었다. 초등학생들은 그들의 편식에 대한 개선 의지가 높은 수준인 것으로 조사되었으므로 $(5,8)$ 향후 지속적인 영양교 육을 실시한다면 장기적으로 아동들의 식생활에서 편식에 대한 개선이 가능하리라 사료된다.

\section{요 약}

본 연구에서는 채소 관련 영양교육의 효과성을 평가하기 위해 경남 창원지역에 소재하는 A초등학교 학생 122명(교 육집단 61명, 비교육집단61명)을 대상으로 2010년 10월 4일 부터 10월 25일까지 4주간 영양교사가 직접 영양교육을 실 시하였으며, 교육집단과 비교육집단을 대상으로 영양교육 전후에 각각 설문조사를 실시하였다. 영양교육의 효과성 평 가를 위해 영양지식(채소 인지도, 채소 관련 영양지식), 채소 기호도, 채소 섭취 행동(채소 섭취 경험 정도, 채소 반찬 섭취 율)의 변화를 분석하였으며 그 결과는 다음과 같다. 첫째, 채소 관련 영양교육이 채소 인지도에 미치는 영향 분석 결과 교육집단과 비교육집단 모두 교육전보다 교육후 채소 인지 도가 유의적으로 높아졌으나 $(\mathrm{p}<0.001)$, 교육집단의 상승폭 이 비교육집단의 상승폭보다 컸다. 또한 채소 관련 영양지식 의 경우 비교육집단에서 유의한 차이가 없었으나 교육집단 에서는 유의한 차이를 보여 $(\mathrm{p}<0.001)$ 영양교육으로 인해 채 소 관련 영양 지식이 높아졌음을 알 수 있었다. 둘째, 채소 기호도의 변화를 분석한 결과 비교육집단에서는 유의한 차 이가 없었으나 교육집단에서는 유의한 차이를 보여 $(\mathrm{p}<$ 0.001) 영양교육이 영양지식의 향상에 효과적인 영향력이 있 음을 알 수 있었다. 셋째, 채소 관련 영양교육이 채소 섭취 경험의 변화에 미치는 영향을 살펴본 결과 비교육집단 $(\mathrm{p}<$ $0.001)$ 과 교육집단 $(\mathrm{p}<0.001)$ 모두에서 유의한 차이를 보였 으나 교육집단에서의 상승폭이 더 크게 나타났다. 즉 채소 관련 영양교육으로 인해 다양한 채소 섭취를 경험하게 됨을
알 수 있었다. 학교급식에서 제공되는 채소 반찬의 섭취율의 변화에 미치는 영향 분석 결과 시금치반찬 $(\mathrm{p}<0.001)$, 배추김 치 $(\mathrm{p}<0.001)$, 깍두기 $(\mathrm{p}<0.001)$ 의 섭취율이 교육집단에서 유 의적으로 증가하는 것을 알 수 있었다. 넷째, 교육집단을 대 상으로 채소 관련 영양교육에 대한 인식을 조사한 결과 조사 대상의 $67.2 \%$ 가 '영양교육수업이 훙미 있었다'고 응답하였 으며, '영양교육 수업이 영양지식의 향상에 도움이 되었다' 는 응답은 $62.3 \%$ 였다. 영양교육 후 채소반찬 제공 시의 섭취 행동에 대해서는 '골고루 조금씩 먹는다'는 응답이 $44.3 \%$ 로 가장 많이 조사되어 채소 관련 영양교육이 학생들에게 긍정 적인 영향을 미치는 것을 알 수 있었다. 본 연구 결과에 의하 면 영양교사에 의한 채소 관련 영양교육이 학생들의 채소 인지도, 채소 관련 영양지식, 채소 기호도, 채소 섭취 경험 및 채소 반찬 섭취율의 변화에 긍정적인 영향을 미치는 것을 알 수 있었다. 본 연구 결과에 근거한 제언은 다음과 같다. 첫째, 본 연구에서는 4 주간의 짧은 교육기간이었음에도 불 구하고 교육집단의 영양지식과 기호도, 섭취율이 향상되는 결과를 제시하였다. 따라서 올바른 식습관 정착을 위해서는 향상된 영양지식을 지속적으로 실천할 수 있도록 장기적인 교육이 필요함을 알 수 있었다. 둘째, 교육 실시 직후 바로 영양교육의 효과를 측정하여 측정시기가 1 회로 그쳤으나 3 개월에서 6 개월 뒤에 측정함으로써 교육 효과의 지속성에 대한 평가가 이루어져야 할 것 같다. 셋째, 지금까지는 일반 적인 영양지식 및 식습관 위주로 영양교육이 이루어졌는데, 향후에는 좀 더 다양한 구체적인 주제별로 체계적인 영양교 육 프로그램 및 교육 체계가 마련되어야 할 것이다.

\section{문 헌}

1. Park JA, Chang KJ. 2004. A study on elementary school teacher's status and recognition of nutrition education in Incheon. Korean J Nutr 37: 928-937.

2. Park JA, Chang KJ. 2004. A study on elementary school dietitian's status and recognition of nutrition education in Incheon. Korean J Community Nutrition 9: 716-724.

3. Chang SO, Lee KS. 1995. The effects of nutrition education on children who avoid to eat vegetables. $J$ Korean Diet Assoc 1: 2-9.

4. Park YH, Kim HH, Shin KH, Shin EK, Bae IS, Lee YK. 2006. A survey on practice of nutrition education and perception for implementing nutrition education by nutrition teacher in elementary schools. Korean J Nutr 39: 403-416.

5. Kim MK. 2010. Analysis of factors to affect the preference and eating attitude of vegetables among elementary school children. MS Thesis. Sangi University, Wonju, Korea. p 29-30, 49-57, 100-104.

6. Kim HJ, Kim HA. 2012. Perception of nutritional education among school administrators, parents, and school nutrition teachers at an elementary school. J Korean Diet Assoc 18: 385-399.

7. Hong YJ. 1998. A study on a relation of food ecology to obesity index of 5 th grade children in Cheju city (II) Obesity index of children and food habit of their mothers-. Korean J Dietary Culture 13: 141-151. 
8. Choi HK. 2003. An analysis of elementary school students' eating habits, taste in food and lunch menus in the Gyeonggi province. MS Thesis. Dongguk University, Seoul, Korea. p $19,41$.

9. Na SY. 2009. A study on vegetables and fruit intakes and related factors among elementary school students. MS Thesis. Seoul Women's University, Gimhae, Korea. p 4143, 71.

10. Chung EJ, Lee SH, Ahn HS. 2009. Vegetable preferences and their association with nutritional knowledge and health-related variables in 5th and 6th grade schoolchildren. J Korean Diet Assoc 15: 83-96.

11. Park MS. 2012. Elementary school students' eating habits and preference of vegetables dishes in school foodservice. MS Thesis. Inje University, Gimhae, Korea. p 38.

12. Na SY, Ko SY, Eom SH, Kim KW. 2010. Intakes and beliefs of vegetables and fruits, self-efficacy, nutrition knowledge, eating behavior of elementary school students in Kyunggi area. Korea J Community Nutrition 15: 329-341.

13. Yoon SJ, Kim HA. 2012. Elementary school students' perception of food waste and factors affecting plate waste rate of school foodservice in the Gyeongnam area. $J$ Korean Diet Assoc 18: 126-140.

14. The Korean Nutrition Society. 2010. Dietary Reference Intakes For Koreans. 1st revision. The Korean Nutrition Society, Seoul, Korea. p 125-126.

15. Ministry of Health \& Welfare, Korea Center for Disease Control and Prevention. 2012. Korea Health Statistics 2011: Korea National Health and Nutrition Examination Survey (KNHANESV-2). Korea Center for Disease Control and Prevention, Seoul, Korea. p 265.

16. Suh YS, Chung YJ. 2010. The effect of nutrition education on the improvement of psychosocial factors related to vegetable and fruit intake of elementary school children in pre-action stages. Korean J Nutr 43: 597-606.

17. Panunzio MF, Antoniciello A, Pisano A, Dalton S. 2007. Nutrition education intervention by teachers may promote fruit and vegetable consumption in Italian students. Nutr Res 27: 524-528.

18. Tuuri G, Zanovec M, Silverman L, Geaghan J, Solmon M, Holston D, Guarino A, Roy H, Murphy E. 2009. "Smart
Bodies" school wellness program increased children's knowledge of healthy nutrition practices and self-efficacy to consume fruit and vegetables. Appetite 52: 445-451.

19. Kang YS. 2003. Study on preference and food science for advanced intake of vegetables for students in elementary school food service. MS Thesis. Kongju National University, Kongju, Korea. p 14-21

20. Park SJ. 2000. The effect of nutrition education program for elementary school children-Especially focused on being familiar with vegetables-. J Korean Diet Assoc 6: 17-25.

21. Yoon HS, Yang HL, Her ES. 2000. Effect of nutrition education program on nutrition knowledge, dietary diversity of elementary school children. Korean J Community Nutrition 5: 513-521

22. Lee MJ. 2009. Nutrition education for behavioral change of vegetable consumption of primary school children in Gyeongnam area. MS Thesis. Kyungnam University, Changwon, Korea. p 57-63.

23. Chae SI. 2005. Marketing research. 3rd ed. B\&M Books, Seoul, Korea. p 134

24. Kim Ryul. 2007. Research methodology for social scientist. Pakyoungsa, Seoul, Korea. p 158.

25. Lee CH. 2008. Research methodology for physical therapists and occupational therapists. 3 rd ed. Gyechookmoonhwasa, Seoul, Korea. p 122.

26. Lee KH. 2001. Research methodology for social sciences. Bobmunsa, Seoul, Korea. p 253.

27. Hur ES, Chae KS, Lee KH, Yang HL, Kang MH, Choi YS, Kim JS, Cho AR, Lee JK, Cho MA. 2010. Fun dietary life. Gyeongsangnamdo Office of Education, Changwon, Korea. p 36-41.

28. Lee SH. 2007. A study on elementary students' intake of vegetables. MS Thesis. Sungshin Women's University, Seoul, Korea. p 8-15, 59-61.

29. Park CI, Ku NS. 1998. Study on food habits of elementary school food service children in Taejon. $J$ Korean Diet Assoc 4: 113-222.

30. Yun YR, Yang EJ. 2010. Effects of nutritional education program through discretional activities in middle school students. Korean J Nutr 43: 489-499.

(2013년 1월 28일 접수; 2013년 2월 26일 채택) 